\title{
Diverse Chromosomal Locations of Quantitative Trait Loci for Tolerance to Maize chlorotic mottle virus in Five Maize Populations
}

\author{
Mark W. Jones, Bryan W. Penning, Tiffany M. Jamann, Jeff C. Glaubitz, Cinta Romay, \\ Edward S. Buckler, and Margaret G. Redinbaugh ${ }^{\dagger}$
}

First, second, and seventh authors: United States Department of Agriculture-Agricultural Research Service (USDA-ARS) Corn, Soybean and Wheat Quality Research Unit, Wooster, OH 44691; third author: Department of Crop Sciences, University of Illinois, Urbana 61801; fourth and fifth authors: Institute for Genomic Diversity, Cornell University, Ithaca, NY 14853; sixth author: USDA-ARS Plant, Soil and Nutrition Research and Department of Plant Breeding and Genetics, Cornell University, Ithaca, NY 14853; and seventh author: Department of Plant Pathology, Ohio State University, Wooster 44691.

Accepted for publication 28 December 2017.

\begin{abstract}
The recent rapid emergence of maize lethal necrosis (MLN), caused by coinfection of maize with Maize chlorotic mottle virus (MCMV) and a second virus usually from the family Potyviridae, is causing extensive losses for farmers in East Africa, Southeast Asia, and South America. Although the genetic basis of resistance to potyviruses is well understood in maize, little was known about resistance to MCMV. The responses of five maize inbred lines (KS23-5, KS23-6, N211, DR, and Oh1 VI) to inoculation with MCMV, Sugarcane mosaic virus, and MLN were characterized. All five lines developed fewer symptoms than susceptible controls after inoculation with MCMV; however, the virus was detected in systemic leaf tissue from each of the lines similarly to susceptible controls, indicating that the lines were tolerant of MCMV rather than resistant to it. Except for KS23-5, the inbred

lines also developed fewer symptoms after inoculation with MLN than susceptible controls. To identify genetic loci associated with MCMV tolerance, large $\mathrm{F}_{2}$ or recombinant inbred populations were evaluated for their phenotypic responses to MCMV, and the most resistant and susceptible plants were genotyped by sequencing. One to four quantitative trait loci (QTL) were identified in each tolerant population using recombination frequency and positional mapping strategies. In contrast to previous studies of virus resistance in maize, the chromosomal positions and genetic character of the QTL were unique to each population. The results suggest that different, genotypespecific mechanisms are associated with MCMV tolerance in maize. These results will allow for the development of markers for marker-assisted selection of MCMV- and MLN-tolerant maize hybrids for disease control.
\end{abstract}

Since 2011, the emergence of maize lethal necrosis (MLN) in sub-Saharan East Africa has substantially increased food insecurity for smallholder farmers in the region. The disease has been confirmed in Kenya, Tanzania, Uganda, Rwanda, Democratic Republic of Congo, and Ethiopia, where it can cause up to $100 \%$ loss of maize crops (De Groote et al. 2016; Lukanda et al. 2014; Mahuku et al. 2015a,b; Wangai et al. 2012). The disease has also recently emerged and spread in China, Taiwan, Ecuador, and Spain (Achon et al. 2017; Deng et al. 2014; Quito-Avila et al. 2016; Xie et al. 2011). MLN results from a synergistic interaction of Maize chlorotic mottle virus (MCMV) with another virus, usually from the family Potyviridae (Niblett and Claflin 1978, Wangai et al. 2012). Because viruses in the Potyviridae family are distributed worldwide, MLN emergence has been closely tied to multiple annual maize crops, the presence of MCMV, and significant populations of a vector, maize thrips (Frankliniella williamsii Hood) (Cabanas et al. 2013; Mahuku et al. 2015a). The development and persistence of the disease may also be associated with transmission of MCMV through seed at rates between 0 and $0.33 \%$, depending on maize germplasm, and through soil (Hilker et al. 2017; Jensen et al. 1991; Mahuku et al. 2015a; Phillips et al. 1982).

With multiple reservoirs and transmission pathways, it is likely that control of MLN will require a multipronged approach, including

${ }^{\dagger}$ Corresponding author: M. G. Redinbaugh; E-mail: redinbaugh.2@osu.edu

Funding: This work was supported, in part, by funds from the National Science Foundation Plant Genome Program (IOS 1238014).

This article is in the public domain and not copyrightable. It may be freely reprinted with customary crediting of the source. The American Phytopathological Society, 2018. vector population control, clean seed, clean soil, and host resistance. However, deployment of virus-resistant hybrids and cultivars will be critical for disease control in areas where subsistence farmers rely on a continuous maize crop for food and have difficulty using insecticides. Few reliable sources of MLN resistance are known. More than $90 \%$ of 25,000 maize entries screened for MLN resistance in 2012 and 2013 were highly susceptible, with just a few inbred lines being moderately resistant (Semagn et al. 2015). Mapping studies using the Improved Maize for African Soils (IMAS) and the Drought-Tolerant Maize For Africa (DTMA) association mapping panels identified 24 singlenucleotide polymorphisms (SNP) on 7 of the 10 maize chromosomes that had small to medium effects on MLN resistance (Gowda et al. 2015). In these studies, plants were screened with a mixture of MCMV and Sugarcane mosaic virus (SCMV); this approach was successful for development of the first-generation MLN-tolerant hybrids and it continues to be used for further genetic characterization of resistance to MLN (Masuka et al. 2017). However, independently dissecting maize resistance to MCMV and potyviruses separately could produce synergistic effects for understanding host-pathogen interactions, leading to MLN resistance and development of highly resistant maize hybrids and cultivars. Maize resistance to potyviruses has been studied extensively over the past 50 years but much less information is available on MCMV resistance in maize.

Highly resistant germplasm and genes or quantitative trait loci (QTL) controlling maize resistance to viruses, especially potyviruses, are well characterized (Redinbaugh and Zambrano Mendoza 2014). Neither the potyviruses SCMV and Maize dwarf mosaic virus (MDMV) nor the unrelated Maize rayado fino virus (MRFV) are detected in systemic leaves of highly resistant inbred lines (Jones et al. 2011; Zambrano et al. 2013), although MDMV and SCMV replicate in inoculated tissues of these lines (Cassone et al. 2014; Law et al. 1989; Lei and Agrios 1986). Across diverse resistant germplasm, 
major genes or QTL on chromosomes 3, 6, and 10 provide resistance to all tested viruses in the family Potyviridae. Recent identification of the two major genes controlling SCMV resistance as an atypical thioredoxin $\mathrm{h}(S c m v 1$ on chromosome 6 ) and auxin binding protein 1 (Scmv2 on chromosome 3 ) provides very tightly linked markers for maize breeders and a basis for investigating the molecular basis of a novel mechanism for virus resistance in plants (Leng et al. 2017; Liu et al. 2017). Similarly, germplasm with strong resistance to other maize-infecting viruses has been identified, and resistance in these lines has been associated with one or a few major QTL that tend to be clustered in specific regions of chromosomes 1, 2, 3, 4, 6, 8, and 10. For MCMV, we hypothesized that resistance would be associated with decreased virus accumulation in systemic leaves and that resistance would be controlled by one or a few consistently identified chromosomal regions in different resistance sources.

MCMV-tolerant lines have been identified in Hawaiian, Thai, and U.S. maize breeding programs (Brewbaker and Martin 2015; Kaeppler et al. 1998), and selected inbred lines from these programs developed the fewest symptoms in screens for MLN resistance in Kenya and MCMV resistance in the United States (Mahuku et al. 2015a). Two additional inbred lines with strong resistance to potyviruses developed reduced or few symptoms after MCMV inoculation. In this study, we characterized the responses of these maize inbred lines to inoculation with MCMV, SCMV, and MLN and examined the effect of resistance on virus accumulation, then selected the best-performing inbred lines for development of biparental populations for mapping resistance to MCMV in maize. The maize inbred line $\mathrm{Oh} 28$ was selected as the susceptible parent for all populations. This line, selected from a cross of $($ CI112-1 $\times$ Oh920 $) \times($ Ill. A $\times$ Ill. B $)$, is highly susceptible to phylogenetically diverse viruses (Redinbaugh and Zambrano Mendoza 2014).

\section{MATERIALS AND METHODS}

Plant materials and population development. Maize inbred lines N211, KS23-5, and KS23-6 (Brewbaker 2009; Kaeppler et al. 1998) were obtained from the North Central Germplasm Introduction Station and maintained in Wooster, OH. Oh1VI was developed and maintained in Wooster (Louie et al. 2002). The inbred line DR was developed from a plant from the Dominican Republic 300 population (PI484035) selected for resistance to Maize chlorotic dwarf virus (MCDV) in Wooster. In 2014, $\mathrm{F}_{2}$ populations were developed from $\mathrm{F}_{1}$ crosses of N211, KS23-5, KS23-6, and DR to the highly virus-susceptible inbred line Oh28. A population of 256 recombinant inbred lines (RIL; S7 to S9) derived from Oh1VI $\times$ Oh28 was previously described (Zambrano et al. 2014a).

Maize responses to virus inoculation. The Kansas isolate of MCMV (Niblett and Claflin 1978) and Ohio isolate of SCMV (Louie 1986) were maintained by serial mechanical inoculation to susceptible maize. SCMV or MCMV inoculum was prepared and used to inoculate leaves of 8- to 10-day-old maize seedlings, as previously described (Louie 1986), except that Marathon (1\% imidacloprid; OHP, Inc., Mainland, PA) at $0.001 \mathrm{~g} / \mathrm{g}$ of soil was included in each pot to control insects. Plants were inoculated twice at a 2-day interval. For the MLN inoculations, plants were inoculated with MCMV and SCMV on sequential days (four inoculations total). Inoculated plants were moved to a growth chamber with cycles of $12 \mathrm{~h}$ of light $\left(600 \mu \mathrm{mol} / \mathrm{m}^{2} / \mathrm{s}\right)$ and $12 \mathrm{~h}$ of darkness and temperatures of 25 and $21^{\circ} \mathrm{C}$, respectively, and individual plants were scored for symptoms beginning 7 to 8 days after the first inoculation and continuing at 2- to 3-day intervals for at least 14 days. A 1-to-5 severity rating scale was used, where $1=$ no symptoms, $2=$ faint chlorotic flecks or mottle, $3=$ full mosaic, $4=$ severe chlorotic mosaic, and $5=$ necrosis or death. Evaluation of maize inbred line responses to MCMV, SCMV, and MLN were conducted independently. Each experiment consisted of a single pot ( 5 kernels/pot) per entry, with three independent replications of the experiment. For evaluating the responses of $\mathrm{F}_{1}$ crosses and parents to MCMV, two pots ( 4 kernels/pot) per entry were used in each of two independent experiments.

Mean disease severity scores were calculated for the seedlings in each pot on each scoring date, then used to calculate area under the disease progress curve (AUDPC) scores, as described (Shaner and Finney 1977). AUDPC/day scores were calculated to account for minor differences in scoring dates among independent experiments and treatments. Analysis of variance was carried out using Proc GLM (SAS ver. 9.3; SAS Institute, Cary NC), and differences among the means for AUDPC/day were identified using Fisher's least significant difference. Pearson correlation coefficients were calculated using the CORREL function in Microsoft Excel (Microsoft Corp., Redmond, WA).

Detection of MCMV in systemic maize leaves. Enzymelinked immunosorbent assay (ELISA) was used to evaluate systemic noninoculated leaves for the presence of MCMV. Leaf tissue was collected from two plants of each inbred line at 16 days after inoculation with $\mathrm{MCMV}$ and stored at $-80^{\circ} \mathrm{C}$. Plants were scored for visual symptom scores prior to tissue collection, and symptomless plants were chosen if present. Leaf samples were extracted into General Extraction Buffer (Agdia, Inc., Elkhart, IN) and evaluated for MCMV using a double-antibody sandwich ELISA kit per the manufacturer's instructions (Agdia, Inc.). Samples were considered positive if the absorbance at $405 \mathrm{~nm}$ after 20 min was twice that of the healthy control. Three independent experiments were done.

Phenotypic analysis of populations. For the $\mathrm{F}_{2}$ populations, 450 to 500 seedlings (3 plants/pot) of each population were inoculated with MCMV as outlined above. Individual plants were rated for symptom development at six dates between 8 and 20 days postinoculation (dpi), and AUDPC scores were calculated for individual plants. Each population screen included the population parents, the $\mathrm{F}_{1}$ cross, and the susceptible hybrid Pa $405 \times \mathrm{Oh} 28$, with mean symptom severity scores for plants within a pot and AUDPC/day scores calculated based as outlined above. For the Oh1VI $\times$ Oh28 RI population, each RIL (253 lines total) was planted (4 plants/pot) and inoculated with MCMV, as outlined above. Symptom development in individual plants was scored four times at 2- to 3-day intervals between 7 and $18 \mathrm{dpi}$. AUDPC/day scores based on the average disease severity for plants within each pot were calculated as outlined above. Three independent evaluations of four seedlings per RIL were carried out.

Genotypic analysis of populations. As symptoms developed in each population, tissue was collected from the 40 to 53 plants first developing symptoms, and used immediately for DNA isolation. At $21 \mathrm{dpi}$, tissue was collected from the 40 to 53 plants having the lowest AUDPC scores, and DNA was isolated. DNA from 90 to 92 $\mathrm{F}_{2}$ plants from each population were selected for genotyping. The 45 to 46 plants with the lowest AUDPC/day scores were selected for the resistant tail; however, if more plants in the population had AUDPC/day scores equal to the highest score in this group, they were also included in the resistant tail. The remaining 90 to 92 DNA selected for genotyping were from plants with the highest AUDPC/ day scores for the population. The AUDPC/day scores for all $\mathrm{F}_{2}$ plants selected for genotypic analysis were more than one standard deviation greater or less than the mean score for the population. For the Oh1VI $\times$ Oh28 RI population, DNA were selected for genotyping from plants of 78 RIL. In this case, tissue was collected from a single plant of individual RIL in the third independent screening replicate. Selection of samples for genotyping of the resistant and susceptible tails was carried out as outlined above. In addition to $F_{2}$ plants and RIL, DNA isolated from the resistant and susceptible parents and $F_{1}$ cross were included in the genotypic analysis.

DNA was isolated from leaf tissue using the Qiagen DNeasy Plant Mini Kit (Qiagen, Mississauga, ON, Canada). DNA was quantified using the Quantifluor dsDNA System (Promega Corp., Madison, WI). Genotyping by sequencing (GBS) was performed at the Genomic Diversity Facility at Cornell University (Ithaca, NY), as described (Elshire et al. 2011). SNP were identified using the Tassel5-GBS 
production pipeline with the ZeaGBSv2.7 Production TOPM (Glaubitz et al. 2014). Genotypes were filtered to remove blanks and control wells and a 'filterAlignMinCount' of 77 was used to filter sites (Bradbury et al. 2007). Genotypes were converted to R/ QTL format using TASSEL5 (Bradbury et al. 2007).

Map construction and QTL analysis based on recombination frequency. Genetic maps for the KS23-6 × Oh28, KS23$5 \times \mathrm{Oh} 28, \mathrm{DR} \times \mathrm{Oh} 28$ and N211 $\times \mathrm{Oh} 28$, and Oh1 VI $\times$ Oh2 $8 \mathrm{RI}$ populations were made in JoinMap v4 (Van Ooijen and Voorrips 2006). Markers with duplicate genotypes, monomorphic markers, and those with $>10 \%$ missing genotypes were eliminated. Map distances were calculated from recombination frequencies using the Kosambi function. QTL identification was done by composite interval mapping (CIM) using WinQTL Cartographer v2.5 (Wang et al. 2010). Standard Method 6 settings were used for CIM: five control markers, a window size of 10 centimorgans $(\mathrm{cM})$, and a walk speed of $2 \mathrm{cM}$, with QTL thresholds $(\alpha=0.05)$ determined using 1,000 permutations (Doerge and Rebai 1996). In each population, all phenotyped individuals were included in the QTL mapping by coding the genotype as "missing information". Further analysis was carried out using RIL from the Oh1VI $\times$ Oh2 8 population for which $<20 \%$ of the GBS marker information was missing. ASMap in $\mathrm{R}$ was used to perform the initial linkage group assignment for the remaining markers using the mstmap.data.frame function with a population type of advanced RIL, map distance in kosambi units, and an initial $P$ value of $1 \mathrm{e}^{-10}$ (Taylor and Butler 2014; R Core Team 2016). Distances between markers were estimated using the quickEst function of ASMap. Marker assignments, locations, and distances were listed using the pull.map function of ASMap. Simple-sequence repeat (SSR) markers of known chromosome location (https://www. MaizeGDB.org) (Andorf et al. 2016) included in the marker data set were used to assign linkage groups to chromosomes, placing broken linkage groups together, and splitting combined linkage groups along large gaps to produce 10 chromosomes. The marker order for the 10 chromosomes was tested and finalized using the ripple function of R/ QTL with emphasis, in order, on fewest double cross-over events, best logarithm of odds (LOD) score, and smallest map size (Broman and Sen 2009). To facilitate identification of closely linked polymerase chain reaction (PCR)-based markers for maize breeders, genotypes for SSR markers in the regions of identified QTL were determined for selected populations (Jones et al. 2004), and the QTL mapping analysis was repeated. Because some SSR markers were the markers most closely associated with a QTL, the results presented include both the GBS SNP and SSR markers.

Genetic maps and QTL identification for the Oh1VI $\times$ Oh28 RI population were done using the R/QTL package (Broman et al. 2003; R Core Team 2016) using BLUPS estimated from the AUDPC/day scores. After import, the dataset was converted to a RIL population using "convert2riself". Markers with <69 typed individuals per marker, that showed segregation distortion, or that were duplicates were removed. Markers were ordered by iteratively changing marker positions in a sliding window using the function "OrderMarkers". Initial marker orders were compared with the physical map and reordered if the physical order had fewer crossovers or an improved likelihood. Further quality control was conducted by discarding single markers that significantly increased the genetic map length (Broman and Sen 2009). Markers were thinned to remove markers at the same genetic position. The final map was estimated using the Kosambi function with an error probability of 0.001. Standard interval mapping was conducted using the QTL package (Broman et al. 2003) implemented in R (R Corp Team 2016). The "scanone" command was used to analyze QTL. In total, 1,000 permutations were used to determine the LOD threshold for significance that corresponds to a $P$ value of 0.10 . QTL with LOD scores above that threshold were considered significant and 1.5 LOD support intervals were calculated using "lodint".

Map construction and QTL analysis based on physical position. GBS genotyped markers of KS23-6 × Oh28, KS23-5 ×
$\mathrm{Oh} 28, \mathrm{DR} \times \mathrm{Oh} 28$, and $\mathrm{N} 211 \times \mathrm{Oh} 28 \mathrm{~F}_{2}$ populations were left in the same order as the physical map of B73 (https://www.MaizeGDB.org) (Andorf et al. 2016). Markers and $F_{2}$ individuals with $>50 \%$ missing data were removed. Markers for all populations were analyzed using the R/QTL package (Broman et al. 2003) for R (R Corp Team 2016). The orderMarkers function was used to test the proper order of SNP markers from sequencing with the B73 map as reference, Est.rf was used to estimate the recombination frequencies, and est.map to estimate the mapping distance in centimorgans with an error probability of 0.001 (Broman et al. 2003). Marker position and parental assignment was assessed by ensuring that likelihood of odds $\times$ recombination fraction graphs in R/QTL had no obvious marker rearrangements on or between chromosomes and by the checkAlleles function. CIM was performed in R/QTL with the $\operatorname{cim}$ function using the Haley-Knott regression method (Haley and Knott 1992) with three marker covariates and a window size of $10 \mathrm{cM}$ (Broman et al. 2003). The 50th highest LOD score from 1,000 permutations of CIM performed in R/QTL by the Haley-Knott regression method (Knott and Haley 2009) was used for an experiment-wide 95\% confidence threshold for each population (Broman and Sen 2009). Dot plots were drawn using the plotPXG function (Broman et al. 2003). Chromosome maps were drawn using the PlotMap function (Broman et al. 2003). QTL traces were drawn in Microsoft Excel (Microsoft Corp.) from data generated by the $\operatorname{cim}$ function (Broman et al. 2003) saved as tab-delimited text files using the write.table function in $\mathrm{R}(\mathrm{R}$ Core Team 2016). Phenotypic variation explained that additive and dominance effects for QTL identified in $\mathrm{F}_{2}$ populations were calculated by the fitqtl function in R/QTL (Broman et al. 2003)

Heritability. For each population, narrow-sense heritability was calculated in TASSEL (Bradbury et al. 2007), with a kinship matrix of all SNP covering the entire genome based on the centered identity by state (IBS) method to reduce overestimation of additive genetic variance (Endelman and Jannink 2012) using the equation heritability = genetic variance/(genetic variance + residual variance). The genetic and residual variances were calculated using the mixed linear model in TASSEL (Zhang et al. 2010). Broad-sense heritability was calculated for the Oh1VI RI population as the variance of the means for the three independent replicates for each line using the VAR.P function in Microsoft Excel (Microsoft Corp.) divided by the total variance calculated as the variance of the means of three replicates for each line plus the mean of the variances of three replicates.

\section{RESULTS}

Responses of maize inbred lines to MCMV, SCMV, and MLN. Inbred lines previously identified as having some resistance or tolerance to the viruses causing MLN, along with RIL derived from a cross of Oh1VI $\times \mathrm{Oh} 28$, were tested for their responses to MCMV, SCMV, and MLN (Table 1). The inbred line Oh28, which has broad susceptibility to maize-infecting viruses, developed clear and severe symptoms after inoculation with MCMV and MLN and clear systemic mosaic symptoms after inoculation with SCMV. The inbred line Pa405, a potyvirus resistance source, had good resistance to SCMV but developed clear and severe symptoms after inoculation with MCMV and MLN, and served as a susceptible control for the latter two diseases. Two lines, N211 and KS23-6, developed few and mild symptoms after inoculation with MCMV, and plants of inbred line Oh1VI and one RIL derived from it (RI70627) also developed fewer symptoms than plants of the susceptible control lines Oh28 and Pa405. The remaining Oh1VIderived RIL and inbred lines DR and KS23-5 were not different than the susceptible control lines in their responses to MCMV. After inoculation with SCMV, AUDPC/day scores for several of the RIL derived from Oh1VI (RI70266, RI70340, and RI70297) and inbred lines KS23-5 and KS23-6 were similar to the susceptible control, Oh28. The remaining lines had lower AUDPC/day scores and all were similar to those for the highly resistant lines Pa405 and Oh1VI. In plants inoculated with MLN (MCMV plus SCMV), N211, KS236 , and Oh1VI developed fewer symptoms than either Oh28 or 
Pa405, and two Oh1VI-derived RIL and DR developed fewer symptoms than Oh28. The responses of the lines to MLN correlated strongly with the responses to $\operatorname{MCMV}(R=0.868, P=0.00025)$ and less strongly with the responses to $\operatorname{SCMV}(R=0.608, P=0.036)$.

Little is known about the accumulation of MCMV in inoculated maize lines developing reduced or no symptoms but it has been suggested that these lines exhibit nearly asymptomatic infection of maize by MCMV (Brewbaker and Martin 2015; Nelson et al. 2011). To determine whether MCMV was present in systemic leaves of the tested inbred lines, samples collected from noninoculated leaves of the inbred lines evaluated for symptom development were assayed for the presence of MCMV using ELISA (Table 2). MCMV was detected in 33 to $100 \%$ of samples collected from inbred lines developing reduced symptoms, and the numbers of positive plants were similar to those obtained for symptomatic Oh28 plants for four of the five lines. The ELISA absorbance values obtained for samples from these MCMV-positive plants were similar to those from symptomatic Oh28 plants. These results indicate the presence of MCMV coat protein in plants of lines expressing few symptoms.

Biparental populations for identifying genetic loci associated with MCMV tolerance. Based on the responses of the inbred lines, $\mathrm{F}_{2}$ populations were developed to characterize the genetics of maize response to MCMV: KS23-6 × Oh28, N211 × Oh28, and DR $\times$ $\mathrm{Oh} 28$. An $\mathrm{F}_{2}$ population was also developed for KS23-5, because it was previously shown to develop fewer symptoms than controls when inoculated with East African MCMV and SCMV isolates (Mahuku et al. 2015a). These and the existing recombinant inbred (RI) population derived from Oh1VI $\times$ Oh28 (Zambrano et al. 2014a) were independently screened for their reactions to MCMV inoculation. AUDPC/day scores for the susceptible parent (inbred line Oh28) ranged from 2.19 to 3.00 across screenings (Table 3), similar to the results obtained in inbred line screening (Table 1) and indicating that susceptible plants developed clear mosaic symptoms by the first scoring date (Table 3 ). Plants of the susceptible $F_{1}$ hybrid $\mathrm{Pa} 405 \times \mathrm{Oh} 28$ were included as a common control, and these had AUDPC/day scores ranging from 2.62 to 3.5 across screenings (data not shown). These results indicate that high disease pressure was attained in each population screening. The responses of the parents, $\mathrm{F}_{1}$, and $\mathrm{F}_{2}$ plants to $\mathrm{MCMV}$ inoculation indicated that AUDPC/day scores for the resistant parents were similar to those obtained in the inbred line screening, and the values for $F_{1}$ and $F_{2}$ plants were between those of the resistant and susceptible parents (Table 3).

The phenotypic distribution of AUDPC/day scores of the $\mathrm{F}_{2}$ or $\mathrm{F}_{2}$-derived plants in each population indicated different patterns

TABLE 1. Responses of maize inbred lines to maize lethal necrosis (MLN) viruses

\begin{tabular}{llll}
\hline & \multicolumn{3}{c}{ AUDPC/day } \\
\cline { 2 - 4 } Line $^{\mathrm{z}}$ & MCMV & SCMV & MLN \\
\hline Pa405 & $4.03 \mathrm{a}$ & $2.46 \mathrm{bc}$ & $3.82 \mathrm{ab}$ \\
Oh28 & $4.02 \mathrm{a}$ & $4.80 \mathrm{a}$ & $4.85 \mathrm{a}$ \\
RI70266 & $3.70 \mathrm{ab}$ & $3.20 \mathrm{ab}$ & $4.06 \mathrm{ab}$ \\
RI70389 & $3.48 \mathrm{abc}$ & $2.75 \mathrm{bc}$ & $3.88 \mathrm{ab}$ \\
RI70340 & $3.32 \mathrm{abc}$ & $3.66 \mathrm{ab}$ & $2.81 \mathrm{bc}$ \\
RI70322 & $2.87 \mathrm{abcd}$ & $2.71 \mathrm{bc}$ & $3.66 \mathrm{ab}$ \\
DR & $2.53 \mathrm{abcd}$ & $2.73 \mathrm{bc}$ & $2.50 \mathrm{bc}$ \\
KS23-5 & $2.39 \mathrm{abcd}$ & $3.23 \mathrm{ab}$ & $3.49 \mathrm{ab}$ \\
Oh1VI & $2.18 \mathrm{bcd}$ & $1.20 \mathrm{c}$ & $1.78 \mathrm{c}$ \\
RI70297 & $1.90 \mathrm{~cd}$ & $3.14 \mathrm{ab}$ & $2.76 \mathrm{bc}$ \\
KS23-6 & $1.55 \mathrm{~d}$ & $3.15 \mathrm{ab}$ & $1.65 \mathrm{c}$ \\
N211 & $1.14 \mathrm{~d}$ & $2.03 \mathrm{bc}$ & $1.57 \mathrm{c}$ \\
\hline
\end{tabular}

y Response of the line to inoculation with Maize chlorotic mottle virus (MCMV), Sugarcane mosaic virus (SCMV), or MCMV plus SCMV (MLN). Values given are the area under the disease progress curve per day (AUDPC/day) for three independent experiments. Values followed by the same letter are not different (least significant difference, $P>0.05$ ).

$\mathrm{z}$ Inbred line or recombinant inbred (RI) line derived from a cross of Oh1VI $\times$ Oh28. for MCMV responses among progeny (Fig. 1). Responses for the $\mathrm{N} 211 \times \mathrm{Oh} 28 \mathrm{~F}_{2}$ and the Oh1VI $\times \mathrm{Oh} 28 \mathrm{RI}$ populations were normally distributed, with the mean and median AUDPC/day being equal. The KS23-6 × Oh28, KS23-5 × Oh28, and DR $\times$ Oh28 F populations were negatively skewed, with population means lower than their median. These phenotypic distributions indicated that QTL analysis was appropriate.

Genetic maps and QTL analysis. Due to the large numbers of $F_{2}$ and $\mathrm{RI}$ individuals phenotyped, selective genotyping was carried out on the resistant and susceptible tails, which consisted of the 38 to 53 individual $F_{2}$ plants or RIL with the lowest and highest AUDPC/day scores, respectively (Table 3) (Darvasi and Soller 1992; Lander and Botstein 1989). The range of AUDPC/day scores for plants used in the resistant and susceptible tails was separated by 0.3 to 2.0 units, depending on the population (Table 3). Genetic maps based on the indicated numbers of individuals and markers were generated using both JoinMap and R/QTL (Table 4). The genetic maps generated using JoinMap, ordered based on lowest recombination frequency, consisted of 10 linkage groups with individual chromosomes ranging from 114 to $263 \mathrm{cM}$ and map sizes of 1,558 to $1,916 \mathrm{cM}$ (Table 4 ).

QTL were identified from the resistant parent in the five populations using QTLCartographer (Table 5). QTL from N211 with LOD scores of 7.6 and 12.9, identified on chromosome 3 and 5, respectively, explained $>37 \%$ of the phenotypic variance. Single QTL on chromosome 6 with LOD scores of 90.1 and 57.9 were identified from KS23-6 and the KS23-5, respectively. These explained a large proportion of the phenotypic variance at 78 and $66 \%$, respectively. The relative positions of the QTL on chromosome 6 were very similar in the two lines. A single QTL with an LOD score of 20.8 that explained nearly $35 \%$ of the phenotypic variance was found in the $\mathrm{DR} \times \mathrm{Oh} 28$ population. Four QTL derived from Oh1VI were found on chromosomes 1, 2, 3, and 10. These QTL had LOD scores of 4.1 to 10 and, together, explained $>56 \%$ of the phenotypic variation. The identified QTL on chromosomes 3 and 10 overlapped with previously identified QTL for resistance to potyviruses and other unrelated viruses in Oh1 VI (Zambrano et al. 2014a,b).

R/QTL was also used to map QTL with genetic maps based on positions of SNP on the B73 physical map v3. Testing of the B73 physical map order with the $\mathrm{N} 211 \times \mathrm{Oh} 28 \mathrm{~F}_{2}$ population and the orderMarkers function in R/QTL indicated that 8 of 855 markers were potentially out of order. However, this did not change map size or the location and strength of QTL significantly. The genetic maps based on marker physical position all had 10 linkage groups with sizes of 225 to $1,305 \mathrm{cM}$ and total map sizes of 3,059 to $9,006 \mathrm{cM}$ (Table 4).

With one exception noted below, all QTL identified using R/QTL came from the resistant parent. For N211, a single QTL on chromosome 5 with an LOD score of 9.6 and explaining $38 \%$ of the phenotypic variation was identified at marker S5_4322924 (Fig. 2A; Table 6). AUDPC scores for heterozygotes were similar to those of individuals with two alleles from N211 (Fig. 2B). For KS23-6 and KS23-5, single QTL on chromosome 6 were identified with LOD

TABLE 2. Detection of Maize chlorotic mottle virus (MCMV) in inbred lines

\begin{tabular}{lcc}
\hline Line & Pos/Tot $^{\mathrm{y}}$ & $\mathrm{A}_{405}{ }^{\mathrm{z}}$ \\
\hline DR & $2 / 6$ & 1.113 \\
KS23-5 & $4 / 6$ & 1.476 \\
KS23-6 & $5 / 6$ & 1.334 \\
N211 & $6 / 6$ & 1.584 \\
Oh1VI & $5 / 6$ & 1.434 \\
Oh28 & $5 / 6$ & 1.158 \\
\hline
\end{tabular}

y Number of enzyme-linked immunosorbent assay (ELISA)-positive plants/ total number of plants assayed. Data are derived from three independent inoculations of two plants each.

$\mathrm{z}$ Mean absorbance at $405 \mathrm{~nm}$ less the absorbance for healthy controls in ELISA for MCMV positive plants. 
scores of approximately 40 that explained nearly all of the phenotypic variation (Fig. 3A and C; Table 6). Two closely linked QTL associated with SNP S6_155627528 and S6_153269049 were identified from KS23-6, and marker S6_156591426 was associated with a QTL from KS23-5 (Fig. 3B, D, and E; Table 6). In both lines, AUDPC scores for individuals with two alleles from Oh28 were similar to heterozygotes (Fig. 3B, D, and E). For DR, a single QTL centered on marker S10_135801262 with an LOD score of approximately 9 explained $31 \%$ of the phenotypic variation (Fig. 2C; Table 6). For this population, AUDPC scores for heterozygotes were intermediate to those of the parents (Fig. 2D). Three QTL were identified in the Oh1VI population: one on chromosome 2 centered on marker S2_163825081, with an LOD score of approximately 10, explained $18 \%$ of phenotypic variance; one on chromosome 3 near marker S3_137246834, with an LOD score of 4.3, explained $16 \%$ of phenotypic variance; and one on chromosome 10 centered on marker S10_134058628, with an LOD score of approximately 9, explained $11 \%$ of the phenotypic variation (Fig. 4 A, C, and E; Table 6). The chromosome 2 QTL identified in the Oh1VI RI population appears associated with the susceptible parent (Fig. 4B, D, and F).

Broad-sense heritability calculated for the Oh1VI RI population using the mean AUDPC/day for RI included in the resistant and susceptible tails was 0.77 , while the broad-sense heritability for the 216 lines for which phenotypic results were obtained for three replicates was 0.66 . Narrow-sense heritability calculated using TASSEL ranged from 0.69 to 0.94 for the $\mathrm{F}_{2}$ and RI populations (Table 4).

\section{DISCUSSION}

Our results indicate that MCMV "resistance" identified in the five inbred lines shares some characteristics with previously characterized virus resistance in maize (e.g., one or a few QTL in each line provide the resistance) but also indicate major differences compared with previous studies. Particular differences include the detection of MCMV in asymptomatic tissues from inoculated resistant lines and differences in the numbers and locations of QTL among the different inbred lines.

Further testing of five lines developing few or late symptoms after inoculation confirmed that inbred lines N211, KS23-5, KS23-6, Oh1VI, and DR might be good sources for MCMV resistance, because they developed fewer symptoms than susceptible controls (Table 1). Although the responses of the lines to MCMV and both SCMV and MCMV (MLN) are not directly comparable because the screens were carried out separately, MLN-inoculated N211, KS236, Oh1 VI, and DR plants also developed fewer symptoms than the susceptible control Oh28, confirming the importance of MCMV in MLN development (Mahuku et al. 2015a). In addition to developing fewer symptoms after MCMV and MLN inoculation, N211, Oh1VI, and DR also had resistance to SCMV, consistent with previous studies (Jones et al. 2007; Zambrano et al. 2014a). In contrast, the SCMV-resistant Pa405 had no resistance to MCMV, suggesting that the responses to these two viruses are not closely linked. Nonetheless, the potential significance of potyvirus resistance to controlling MLN can be seen in Oh1VI, which is highly resistant to potyviruses (Jones et al. 2007; Zambrano et al. 2014a) but only moderately resistant to MCMV (Table 1).

Plants can fend off pathogens by either reducing or restricting pathogen growth (resistance) or by reducing or moderating pathogen effects (tolerance) (Boots 2008; Roy and Kirchner 2000). To determine whether the five lines had resistance or tolerance to MCMV, we tested systemic leaf tissue from the five inbred lines for the presence of MCMV and determined that ELISA responses for tissue of inoculated plants from the five lines and the susceptible control (Oh28) were similar. Because $0.1 \mu \mathrm{g}$ to $100 \mu \mathrm{g}$ of MCMV protein produces similar responses in the ELISA used (M. G. Redinbaugh, unpublished results), these results cannot be considered quantitative. Nonetheless, the detection of MCMV in all five lines suggests that they have tolerance to MCMV rather than resistance. Although deploying either resistant or tolerant materials could reduce yield losses associated with MLN, deployment of resistant materials reduces the amount of pathogen in the landscape whereas use of tolerant materials tends to increase pathogen levels (Miller et al. 2006). The tolerance to MCMV characterized here presents a potentially significant tool for disease management but it will be important to determine whether MCMV accumulates to lower levels in these lines and to understand the effects of concurrent potyvirus infection on MCMV accumulation.

In contrast to previous studies with other maize-infecting viruses, preliminary results suggested that MCMV tolerance might not have genetic similarity across the five maize lines (data not shown). Because MCMV is not known in Ohio, United States Department of Agriculture Animal and Plant Health Inspection Service permits required that screening for responses to MCMV be done under controlled conditions. Therefore, $\mathrm{F}_{2}$ populations for four of the lines were developed to complement the existing Oh1VI $\times$ Oh28 RI population, and all five populations were screened for their responses to MCMV in a growth chamber. The distribution of phenotypes among $\mathrm{F}_{2}$ individuals and RIL was dependent on the tolerant parent, and was skewed toward the susceptible parent for the KS23-6, KS235 , and DR populations. In contrast, phenotypes appeared to be more normally distributed for the N211 and Oh1VI populations. These differences highlighted the need to assess all five populations for genes and QTL associated with MCMV tolerance.

Although the distributions of AUDPC scores were not normal for the KS23-6, KS23-5, and DR populations, no transformation of the data was done prior to QTL analysis. Regression interval mapping methods such as CIM do not require assumption of normality of errors and are not significantly affected by nonnormal trait distributions when using permutation analysis to set a threshold of significance (Churchill and Doerge 1994; Rebaï 1997; Zeng 1994). Furthermore, regression interval mapping of small nontransformed populations can have greater power to detect QTL over small normalized populations (Rebaï 1997).

TABLE 3. Responses of maize populations to Maize chlorotic mottle virus inoculation ${ }^{\mathrm{u}}$

\begin{tabular}{|c|c|c|c|c|c|c|c|c|c|}
\hline Population $^{\mathrm{v}}$ & $\mathrm{R}$ parent & $\mathrm{S}$ parent & $\mathrm{F}_{1}$ & $\mathrm{~F}_{2}$ & $N^{\mathrm{w}}$ & $\operatorname{Ind}^{\mathrm{x}}$ & $\mathrm{R}$ tail $(n)^{\mathrm{y}}$ & $\mathrm{S}$ tail $(n)^{\mathrm{y}}$ & $\mathrm{R}$ tail $(\%)^{\mathrm{z}}$ \\
\hline $\mathrm{N} 211 \mathrm{~F}_{2}$ & 1.00 & 3.63 & 2.40 & 2.21 & 489 & $48 / 42$ & $1.0-1.5$ & $2.4-3.4$ & 9.8 \\
\hline $\mathrm{DR} \mathrm{F}_{2}$ & 1.00 & 2.19 & 1.46 & 2.46 & 462 & $53 / 39$ & $1.0-1.8$ & $2.8-3.5$ & 11.5 \\
\hline $\mathrm{KS} 23-5 \mathrm{~F}_{2}$ & 1.44 & 3.00 & 2.33 & 2.34 & 515 & $47 / 43$ & $1.0-1.3$ & $2.8-3.6$ & 9.1 \\
\hline $\mathrm{KS} 23-6 \mathrm{~F}_{2}$ & 1.00 & n.d. & 1.40 & 2.32 & 499 & $46 / 46$ & $1.0-1.0$ & $2.9-3.6$ & 9.3 \\
\hline Oh1VI RI & 1.20 & 2.75 & 2.30 & 2.52 & 244 & $40 / 38$ & $1.2-2.1$ & $2.4-4.4$ & 18.4 \\
\hline
\end{tabular}

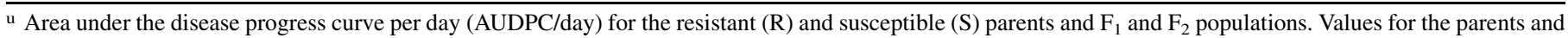
$\mathrm{F}_{1}$ are the mean AUDPC/day for one pot of four plants. For the Oh1VI population, the mean AUDPC/day 256 recombinant inbred lines (mean for three independent experiments, as outlined in the Materials and Methods) is given; n.d. = not determined.

$\checkmark$ The indicated maize inbred line was crossed to line $\mathrm{Oh} 28$, and $\mathrm{F}_{2}$ or recombinant inbred (RI) populations were developed.

${ }^{w}$ Number of $F_{2}$ plants from which the $F_{2}$ mean AUDPC/day was derived. The $\mathrm{R}$ and $\mathrm{S}$ tails were drawn from this set of $\mathrm{F}_{2}$ plants for genotyping.

$x$ Number of individuals (Ind) in the R/S tails, respectively.

y Range of AUDPC/day values for plants pooled in the R and S tails.

$\mathrm{z}$ Percentage of the population represented by the $\mathrm{R}$ tail. 
For single traits, genotyping individuals in the upper and lower $25 \%$ of the population's phenotypic range allows for identification of QTL without significant loss of detection power, although the amount of variation attributable to the QTL may be overestimated (Darvasi and Soller 1992; Sillanpää and Hoti 2007). Therefore, selective genotyping of resistant and susceptible tails was chosen for genetic characterization of the five $\mathrm{F}_{2}$ or RI populations so that QTL could be rapidly and efficiently identified. Selective genotyping also allowed us to use information from the larger phenotyped populations for identifying loci associated with MCMV tolerance in a cost-effective manner and to correct for allele effect size estimates (Lander and Botstein 1989). Broad-sense heritability in the Oh1VI RI population of 0.77 for the resistant and susceptible tails and 0.66 for all phenotyped RIL, and narrow-sense heritability in the five populations between 0.69 and 0.94 (Table 4), indicate that most of the phenotypic variation observed was due to genetic variability. Because only the upper and lower tails of disease severity for each population were genotyped, some overestimation of narrow-sense heritability using TASSEL due to narrowed genotypic diversity near the locations affecting phenotype cannot be ruled out. However, heritability was controlled for overestimation as much as possible by choosing the centered IBS method of predicting the kinship matrix and using the entire set of markers for each population covering the full genome, as suggested by Endelman and Jannink (2012).

Each of the five populations responded differently to MCMV inoculation, with significant differences in both the character of tolerance and the numbers and chromosomal locations of resistance loci. Using mapping approaches based on either recombination frequency (Table 5) or genomic positions of SNP on the B73 physical map (Table 6), QTL were identified on chromosomes 3 (Oh1VI), 5 (N211), 6 (KS23-5 and KS23-6), and 10 (DR and Oh1VI). Because KS23-5 and KS23-6 were selected from KS23 (a broadbase synthetic developed from 26 inbred lines) (Jampatog et al. 2010), it is possible that the QTL on chromosome 6 carried by both is from the same source. If this is the case, then at least four unique patterns for resistance were observed: large-effect QTL on chromosomes 5 (N211), 6 (KS23 lines), and 10 (DR) and the multiple smaller QTL observed in Oh1IV. This is in contrast to resistance loci identified for other maizeinfecting viruses, which tend to occur in the same chromosomal locations in diverse germplasm (Redinbaugh and Zambrano Mendoza 2014). It will be important to determine whether pyramiding of the loci identified in this study will produce a highly tolerant or even a resistant line.

Very large QTL effects were identified, especially for the KS236 and KS23-5 populations, where $R^{2}$ ranged from 0.66 to 0.98 depending on the line and mapping approach used. Factors contributing to large QTL effects include screening $F_{2}$ populations, the use of controlled environments, and the recessive nature of the resistance. Important sources for overestimation of QTL effects are the selective genotyping approach used and the relatively small numbers of individuals genotyped. Selective genotyping may also select against recombinants, reducing the effective recombination rate near QTL and potentially causing bias in linkage map construction (Lin and Ritland 1996). However, population size has a larger effect on linkage maps, with approximately a threefold increase in calculated marker distances resulting from reducing the population size from 800 to 100 RIL (Silva et al. 2007). The relatively small populations used in this study likely influenced the increased linkage group sizes in maps based on SNP position in the B73 genome. In addition, genome rearrangements or deletions, often spanning megabases, that occur between maize inbred lines (Brunner et al. 2005; Fu and Dooner 2002; Song and Messing 2003; Springer et al. 2009) can cause markers on position-based maps to be out of place due to rearrangements in the genome of the inbred lines used in the study, further increasing map distances. To account for this possibility, we arranged markers based on both genomic position and recombination frequency, and identified QTL in similar chromosomal locations (Tables 5 and 6). Although further research to verify the activity of these QTL in large replicated field trials is required, these results provide markers and germplasm for population development.

Overlap in MCMV-tolerant QTL was observed, with loci at similar positions identified on chromosome 10 in the DR and

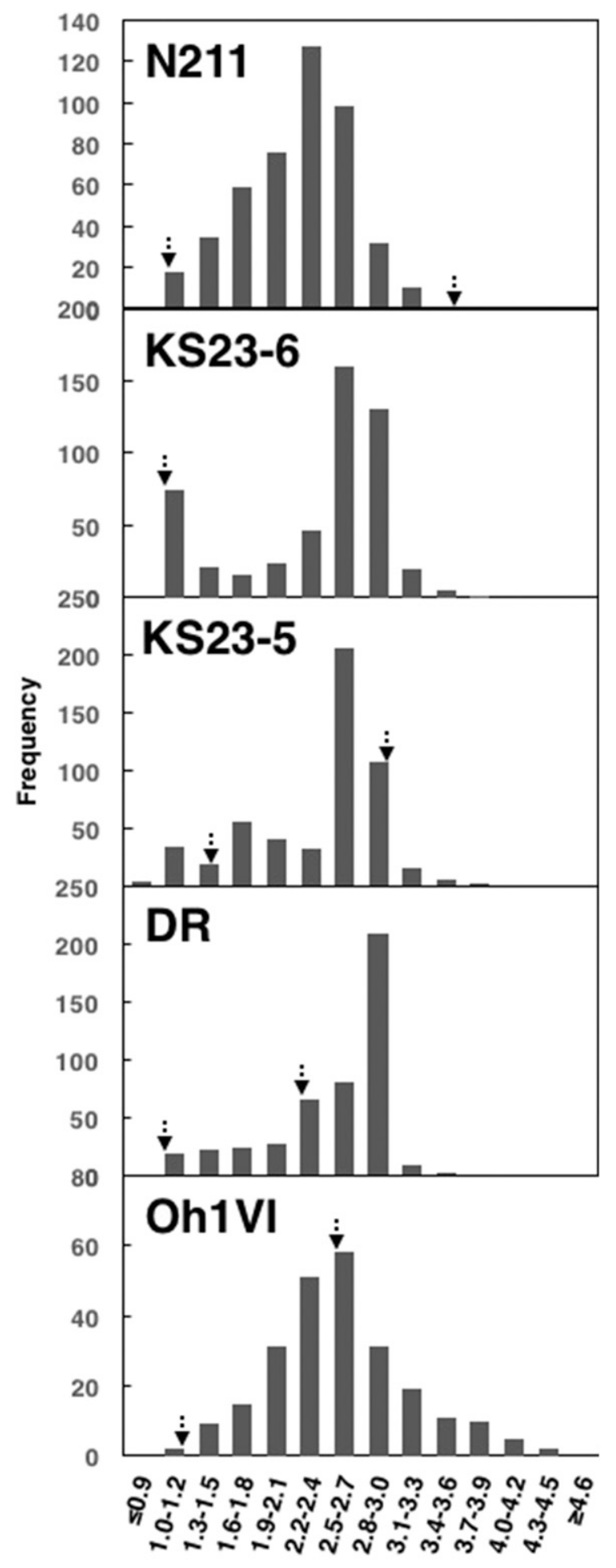

\section{Severity Rating}

Fig. 1. Distribution of maize response to Maize chlorotic mottle virus in maize populations. Panels show responses for $\mathrm{F}_{2}$ populations of DR, N211, KS23-6, and $\mathrm{KS} 23-5$ crossed to $\mathrm{Oh} 28$, and a recombinant inbred population derived from Oh1VI $\times$ Oh28. Responses of resistant and susceptible parents included as controls in the screens are indicated as dashed arrows. For KS23-6, the response of the susceptible parent was not determined. 
TABLE 4. Genetic map properties

\begin{tabular}{|c|c|c|c|c|c|c|c|}
\hline \multirow[b]{2}{*}{ Population } & \multirow[b]{2}{*}{ Map } & \multirow[b]{2}{*}{ Markers $(n)$} & \multicolumn{2}{|c|}{ Chromosomes $(\mathrm{cM})^{\mathrm{w}}$} & \multicolumn{2}{|c|}{ Variation } & \multirow[b]{2}{*}{$h^{2 \mathrm{z}}$} \\
\hline & & & Range & Total & Genetic $^{\mathrm{x}}$ & Residual $^{\mathrm{y}}$ & \\
\hline \multirow[t]{2}{*}{$\mathrm{N} 211 \times \mathrm{Oh} 28 \mathrm{~F}_{2}$} & JoinMap v. 4 & 467 & $154-263$ & 1,916 & $\ldots$ & $\ldots$ & $\ldots$ \\
\hline & RQTL & 856 & $576-1,305$ & 9,006 & 42.32 & 5.54 & 0.88 \\
\hline \multirow[t]{2}{*}{$\mathrm{KS} 23-6 \times \mathrm{Oh} 28 \mathrm{~F}_{2}$} & JoinMap v. 4 & 374 & $114-226$ & 1,761 & $\ldots$ & $\ldots$ & $\ldots$ \\
\hline & RQTL & 835 & $601-1,205$ & 8,430 & 78.40 & 12.37 & 0.86 \\
\hline \multirow[t]{2}{*}{$\mathrm{KS} 23-5 \times \mathrm{Oh} 28 \mathrm{~F}_{2}$} & JoinMap v. 4 & 1,011 & $127-235$ & 1,599 & $\ldots$ & $\ldots$ & $\ldots$ \\
\hline & RQTL & 1,849 & $243-416$ & 3,307 & 119.45 & 7.83 & 0.94 \\
\hline \multirow[t]{2}{*}{$\mathrm{DR} \times \mathrm{Oh} 28 \mathrm{~F}_{2}$} & JoinMap v. 4 & 767 & $135-183$ & 1,558 & $\ldots$ & $\ldots$ & $\ldots$ \\
\hline & RQTL & 731 & $615-1,222$ & 8,505 & 24.28 & 10.95 & 0.69 \\
\hline \multirow[t]{2}{*}{ Oh1VI RI } & JoinMap v. 4 & 853 & $145-261$ & 1,808 & $\ldots$ & $\ldots$ & $\ldots$ \\
\hline & RQTL & 873 & $225-424$ & 3,059 & 0.325 & 0.021 & 0.94 \\
\hline
\end{tabular}

${ }^{\text {w }}$ Chromosomes in centimorgans (cM).

x Genetic variation associated with the narrow-sense heritability calculated in TASSEL by kinship.

y Residual variation associated with the narrow-sense heritability calculated in TASSEL.

z Narrow-sense heritability calculated in TASSEL.

TABLE 5. Quantitative trait locus (QTL) analysis of Maize chlorotic mottle virus response in maize populations with markers arranged by recombination frequency ${ }^{\mathrm{w}}$

\begin{tabular}{|c|c|c|c|c|c|c|c|c|c|}
\hline Population & Chr & Size & Pos & Range & Closest marker ${ }^{\mathrm{x}}$ & $\mathrm{LOD}^{\mathrm{y}}$ & Add & Dom & $R^{2 \mathrm{z}}$ \\
\hline \multirow[t]{2}{*}{$\mathrm{N} 211 \times \mathrm{Oh} 28 \mathrm{~F}_{2}$} & 3 & 189 & 64 & $53-65$ & S3_146598418 & 7.6 & 2.40 & 1.05 & 0.135 \\
\hline & 5 & 172 & 27 & $22-36$ & bnlg143 (5.9 Mb) & 12.9 & 2.93 & 2.39 & 0.236 \\
\hline $\mathrm{KS} 23-6 \times \mathrm{Oh} 28 \mathrm{~F}_{2}$ & 6 & 149 & 106 & $97-110$ & umc1859 $(158.5 \mathrm{Mb})$ & 90.1 & 9.55 & 8.69 & 0.783 \\
\hline $\mathrm{DR} \times \mathrm{Oh} 28 \mathrm{~F}_{2}$ & 10 & 135 & 64 & $57-76$ & S10_135801262 & 20.8 & 0.87 & 2.07 & 0.347 \\
\hline \multirow{3}{*}{ Oh1VI RI } & 1 & 261 & 127 & $123-129$ & S1_187667824 & 4.4 & $\ldots$ & $\ldots$ & 0.105 \\
\hline & 2 & 210 & 125 & $115-135$ & S2_15838874 & 10.0 & $\ldots$ & $\ldots$ & 0.210 \\
\hline & 3 & 185 & 72 & 70-78 & S3_135306398 & 4.1 & $\ldots$ & $\ldots$ & 0.090 \\
\hline
\end{tabular}

${ }^{\mathrm{w}}$ For the $\mathrm{F}_{2}$ populations, maps were generated and QTL identified using JoinMap v4 (Van Ooijen and Voorrips 2006) and WinQTL Cartographer 2.5 (Wang et al. 2010). For the recombinant inbred (RI) population, the R/QTL package implemented in R was used (Broman et al. 2003; R Core Team 2016). Chromosome (Chr) size, position (Pos), and range are given in centimorgans. Add = additive and Dom $=$ dominance.

x Closest single-nucleotide polymorphism or simple-sequence repeat (SSR) marker. For SSR markers, the position of the marker in the B73 genome is also given.

${ }^{y}$ Likelihood of odds (LOD) score. Thresholds of significance, determined by 1,000 permutations at $\alpha \leq 0.05$, were 5.6, 51.1, 25.8, 2.5, and 3.0 for the N211-, KS23-6-, KS23-5-, DR-, and Oh1VI-derived populations, respectively.

${ }^{\mathrm{z}} R^{2}=$ the proportion of the phenotypic variance explained by the QTL.
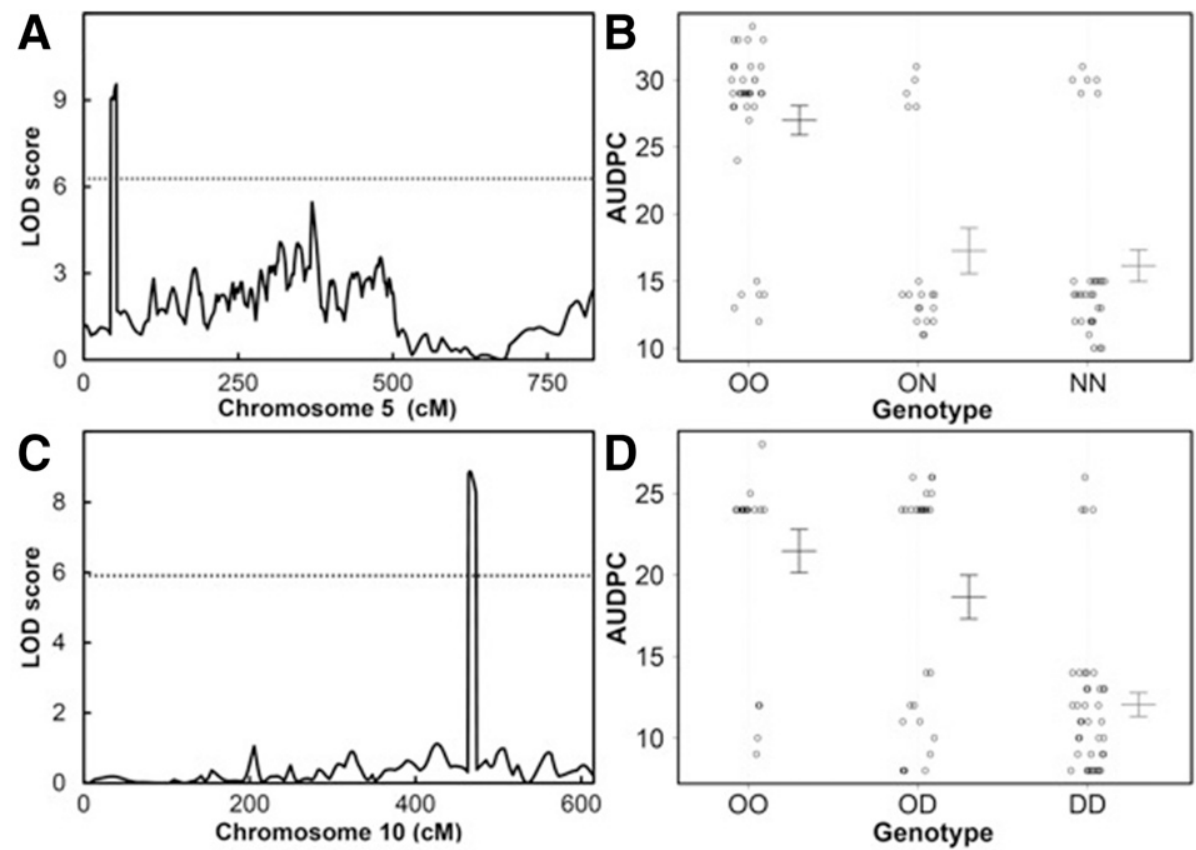

Fig. 2. Loci for Maize chlorotic mottle virus tolerance in the $\mathrm{N} 211 \times \mathrm{Oh} 28$ and $\mathrm{DR} \times \mathrm{Oh} 28 \mathrm{~F}_{2}$ populations. A, Likelihood of odds (LOD) scan showing the single quantitative trait locus (QTL) identified on chromosome 5 and $\mathbf{B}$, dot plot for the closest marker are shown for the N $211 \times$ Oh 28 population. Similarly, C, an LOD scan showing the single QTL identified on chromosome 10 and $\mathbf{D}$, a dot plot for the closest marker are shown for the DR $\times$ Oh28 population. 
Oh1VI populations and on chromosome 3 in the Oh1VI and N211 populations. In the Oh1VI $\times$ Oh28 population, the QTL on chromosome 3 overlaps with previously mapped loci for potyvirus, Maize mosaic virus, and MCDV resistance, while chromosome 10
QTL overlaps with previously mapped loci for potyvirus, MCDV, MRFV, and Maize necrotic streak virus (MNeSV) resistance (Jones et al. 2004; Zambrano et al. 2014a,b). Like MCMV, MNeSV is in the family Tombusviridae, suggesting that the QTL might provide

TABLE 6. Quantitative trait locus (QTL) analysis of Maize chlorotic mottle virus response in maize populations with markers arranged by physical location ${ }^{\mathrm{x}}$

\begin{tabular}{|c|c|c|c|c|c|c|c|c|c|}
\hline Population & Chr & Size & Pos & Range & Closest marker & LOD $^{y}$ & Add & Dom & $R^{2 \mathrm{z}}$ \\
\hline $\mathrm{N} 211 \times \mathrm{Oh} 28 \mathrm{~F}_{2}$ & 5 & 825 & 53 & 44-53 & S5_4322924 & 9.6 & -5.50 & -4.45 & 0.38 \\
\hline $\mathrm{KS} 23-6 \times \mathrm{Oh} 28 \mathrm{~F}_{2}$ & 6 & 630 & 570 & $545-573$ & S6_155627528 & 42.3 & -12.03 & 11.37 & 0.98 \\
\hline $\mathrm{KS} 23-5 \times \mathrm{Oh} 28 \mathrm{~F}_{2}$ & 6 & 243 & 188 & $183-193$ & S6_156591426 & 39.8 & -12.20 & 10.31 & 0.94 \\
\hline $\mathrm{DR} \times \mathrm{Oh} 28 \mathrm{~F}_{2}$ & 10 & 615 & 467 & $464-474$ & S10_135801262 & 8.9 & -4.70 & 2.09 & 0.31 \\
\hline \multirow[t]{3}{*}{ Oh1VI RI } & 2 & 424 & 292 & $270-361$ & S2_-163825081 & 10.3 & $\ldots$ & $\ldots$ & 0.18 \\
\hline & 3 & 300 & 107 & $106-108$ & S3_137246834 & 4.3 & $\ldots$ & $\ldots$ & 0.16 \\
\hline & 10 & 225 & 119 & $111-139$ & S10_134058628 & 8.7 & $\ldots$ & $\ldots$ & 0.11 \\
\hline
\end{tabular}

${ }^{\mathrm{x}}$ For all populations, single-nucleotide polymorphism markers obtained from genotyping by sequencing were ordered by their positions on the B73 physical map. QTL were identified using the R/QTL package for R (Broman et al. 2003; R Core Team 2016). Chromosome (Chr) size, position (Pos), and range are given in centimorgans. Add $=$ additive and Dom $=$ dominance.

${ }^{y}$ Likelihood of odds (LOD) score. Thresholds of significance, determined by 1,000 permutations at $\alpha \leq 0.05$, were 6.3, 6.1, 5.9, 5.9, and 4.2 for the N211-, KS23-6-, KS23-5-, DR-, and Oh1VI-derived populations, respectively.

${ }^{\mathrm{z}} R^{2}=$ the proportion of the phenotypic variance explained by the QTL.
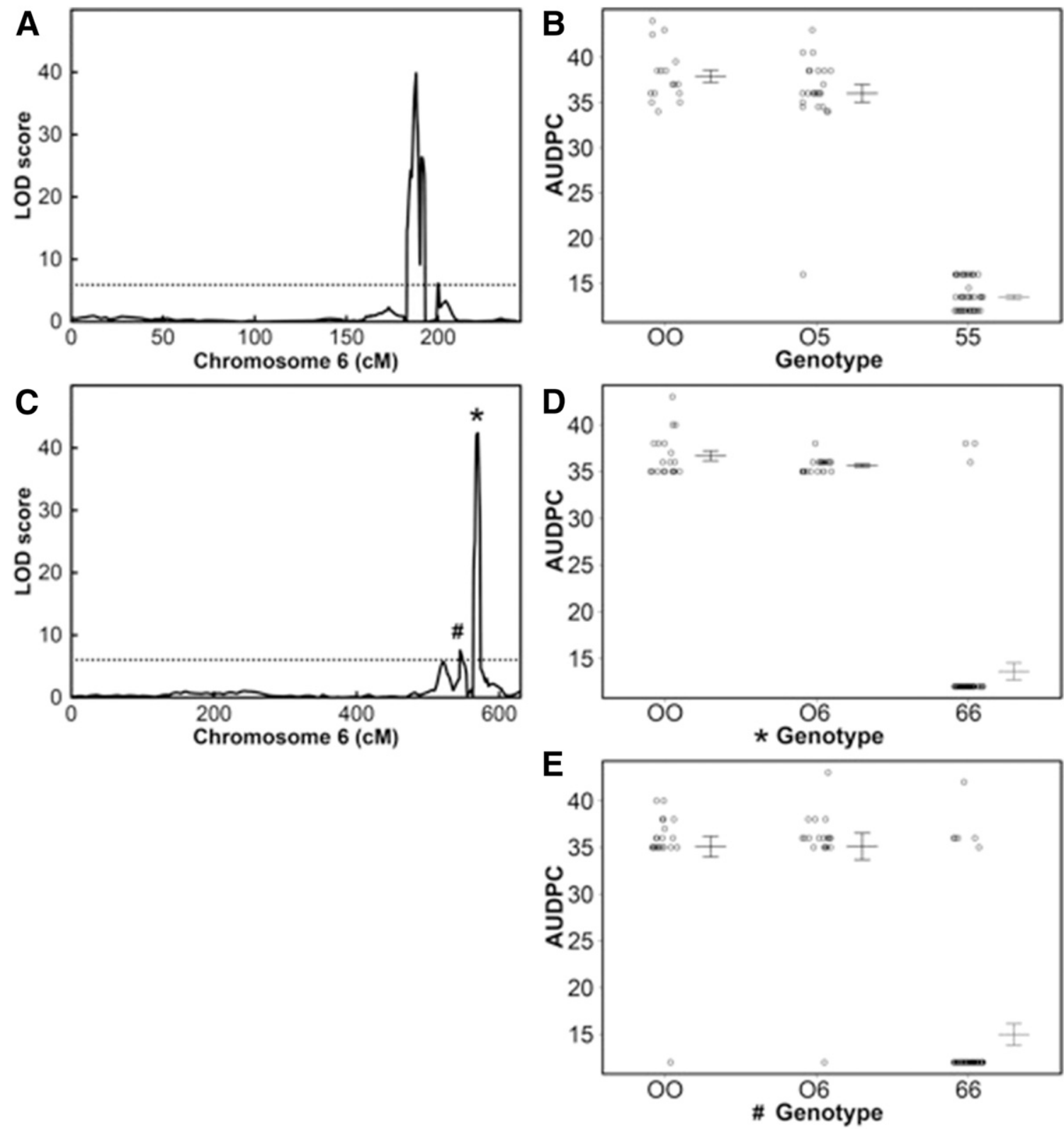

Fig. 3. Chromosome 6 loci for Maize chlorotic mottle virus tolerance detected in the KS23-5 $\times$ Oh2 28 and KS23-6 $\times$ Oh $28 \mathrm{~F}_{2}$ populations. Likelihood of odds (LOD) scans showing chromosome six loci identified in the A, KS23-5 and C, KS23-6 populations. B, Dot plot of closest markers in the KS23-5 population. D and E, Dot plots of the closest marker to the two peaks in KS23-6 population. The marker in D was associated with the larger peak and the smaller peak in E. 
resistance across viruses within the same family; however, further work is needed to define these loci. More broadly, the MCMV tolerance loci identified on chromosomes 2, 3, and 10 fall within virus-resistance clusters identified across germplasm and diverse viruses (Redinbaugh and Zambrano Mendoza 2014). The Oh1VI QTL on chromosome 2 is in a chromosomal location similar to loci for resistance to maize-infecting fijiviruses and Maize stripe virus in unrelated germplasm (Dintinger et al. 2005a; Luan et al. 2012; Martin et al. 2010).

The distribution of phenotypes in the $\mathrm{F}_{2}$ and RI populations and the phenotypes of $\mathrm{F}_{2}$ plants heterozygous for closely linked markers indicated some differences in the action of genes controlling MCMV tolerance. For KS23-5 and KS23-6, the phenotypes of the $F_{2}$ population were skewed toward the susceptible parent (Fig. 1) and the AUDPC scores of plants heterozygous for the markers closely linked to the chromosome 6 QTL were similar to those of the susceptible parent (Fig. 3), suggesting that tolerance is controlled by a recessive gene. Phenotypic distribution and AUDPC scores for plants in the DR $\mathrm{F}_{2}$ population were also skewed toward the susceptible parent, suggesting a recessive character for genes controlling this QTL (Fig. 2). In contrast, plants heterozygous at markers linked to the chromosome 5 QTL in the $\mathrm{N}_{2} 11 \mathrm{~F}_{2}$ population had AUDPC scores similar to the resistant parent, suggesting a dominant character for genes in this QTL (Fig. 2). The distribution of MCMV tolerance in RIL from the Oh1VI population appears to be more normally distributed, which is consistent with the identification of several QTL with smaller contributions to tolerance in this line.

In an association mapping study using DTMA and IMAS panels, 6 and 18 markers, respectively, were identified as significantly associated with MLN resistance, including markers on chromosomes 1, 2, 3, 5, 6, and 10 (Gowda et al. 2015). Chromosome 1 markers at $148 \mathrm{Mb}$ were identified in both the IMAS population and the Oh1VI $\times$ Oh28 population. Similarly, markers were identified on the short arm of chromosome 5 in the DTMA population and the
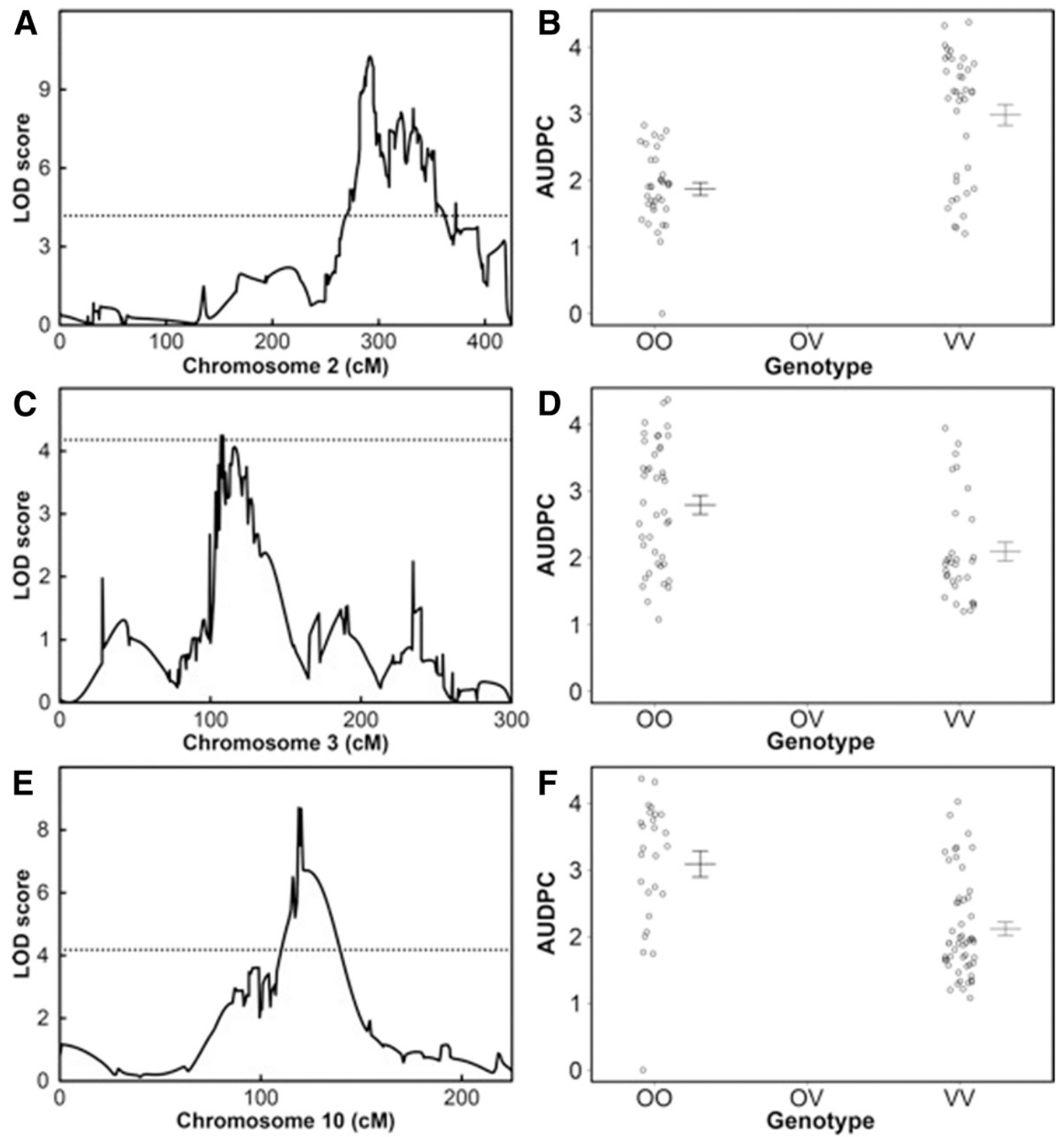

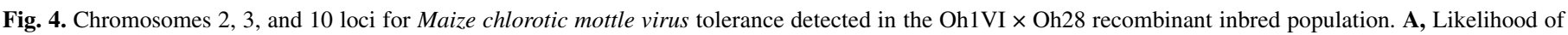

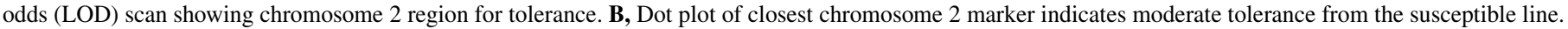

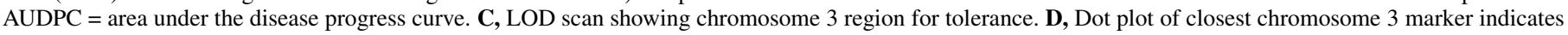

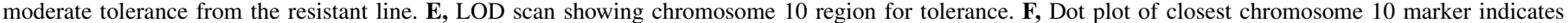
moderate tolerance from the resistant line. 
$\mathrm{N} 211 \times$ Oh28 population. The chromosomal positions of markers on chromosomes 2,3 , and 6 were different between the studies. Thus, at least some of the loci identified in an MLN screen conducted under field conditions using older plants may also be present in seedlings screened under controlled conditions with MCMV. Previous studies with potyviruses and MRFV indicate that resistance identified under controlled conditions is also active in the field (Jones et al. 2011; Vandeplas 2003).

Taken together, these results indicate that maize responses to MCMV are quite different than those described for other viruses. Lines developing no or few symptoms were identified, and these lines developed significantly fewer symptoms when inoculated with MLN regardless of whether the line was also resistant to SCMV. The detection of virus in inoculated but symptom-free plants indicates that these lines are tolerant of the virus rather than resistant to it, in contrast to other maize-virus systems in which systemic viral movement is limited. Further, the chromosomal locations and activities of QTL differed among populations rather than occurring at similar locations. The unique mechanisms associated with MCMV tolerance warrant further study, particularly quantitative investigation of the effects of tolerance on MCMV accumulation and the influence of secondary virus infection on virus tolerance. Identification of specific genes associated with virus tolerance will require further research. More practically, understanding the effects of multiple QTL for tolerance on virus accumulation, interactions with secondary viruses, and agronomic performance will be useful for plant breeders working to control MLN. In addition, markers and germplasm resources identified in this study can be used in conjunction with well-defined markers for potyvirus resistance in maize to develop marker-assisted selection for MLN-resistant hybrid and cultivar development.

\section{ACKNOWLEDGMENTS}

We thank K. Barriball and J. Todd for expert assistance with the ELISA analyses and germplasm development, respectively.

\section{LITERATURE CITED}

Achon, M. A., Serrano, L., Clemente-Orta, G., and Sossai, S. 2017. First report of Maize chlorotic mottle virus on a perennial host, Sorghum halepense, and maize in Spain. Plant Dis. 101:393.

Andorf, C. M., Cannon, E. K., Portwood, I. I. J. L., Gardiner, J. M., Harper, L. C., Schaeffer, M. L., Braun, B. L., Campbell, D. A., Vinnakota, A. G., Sribalusu, V. V., Huerta, M., Cho, K. T., Wimalanathan, K., Richter, J. D., Mauch, E. D., Rao, B. S., Birkett, S. M., Sen, T. Z., and Lawrence-Dill, C. J. 2016. MaizeGDB update: New tools, data and interface for the maize model organism database. Nucleic Acids Res. 44:D1195-D1201.

Boots, M. 2008. Fight or learn to live with the consequences? Trends Ecol. Evol. 23:248-250

Bradbury, P. J., Zhang, Z., Kroon, D. E., Casstevens, T. M., Ramdoss, Y., and Buckler, E. S. 2007. TASSEL: Software for association mapping of complex traits in diverse samples. Bioinformatics 23:2633-2635.

Brewbaker, J. L. 2009. Registration of nine maize populations resistant to tropical diseases. J. Plant Regist. 3:10-13.

Brewbaker, J. L., and Martin, I. 2015. Breeding tropical vegetable corns. Pages 125-198 in: Plant Breeding Reviews, Vol. 39. J. Janick, ed. John Wiley \& Sons, Inc., Hoboken, NJ.

Broman, K. W., and Sen, S. 2009. A Guide to QTL Mapping with R/QTL. Springer, New York.

Broman, K. W., Wu, H., Sen, Ś., and Churchill, G. A. 2003. R/QTL: QTL mapping in experimental crosses. Bioinformatics 19:889-890.

Brunner, S., Fengler, K., Morgante, M., Tingey, S., and Rafalski, A. 2005. Evolution of DNA sequence nonhomologies among maize inbreds. Plant Cell 17:343-360.

Cabanas, D., Watanabe, S., Higashi, C. H. V., and Bressan, A. 2013. Dissecting the mode of Maize chlorotic mottle virus transmission (Tombusviridae: Machlomovirus) by Frankliniella williamsi (Thysanoptera: Thripidae). J. Econ. Entomol. 106:16-24.

Cassone, B. J., Chen, Z. B., Chiera, J., Stewart, L. R., and Redinbaugh, M. G. 2014. Responses of highly resistant and susceptible maize to vascular puncture inoculation with Maize dwarf mosaic virus. Physiol. Mol. Plant Pathol. 86:19-27.
Churchill, G. A., and Doerge, R. W. 1994. Empirical threshold values for quantitative trait mapping. Genetics 138:963-971.

Darvasi, A., and Soller, M. 1992. Selective genotyping for determination of linkage between a marker locus and a quantitative trait locus. Theor. Appl. Genet. 85:353-359.

De Groote, H., Oloo, F., Tongruksawattana, S., and Das, B. 2016. Communitysurvey based assessment of the geographic distribution and impact of maize lethal necrosis (MLN) disease in Kenya. Crop Prot. 82:30-35.

Deng, T. C., Chou, C. M., Chen, C. T., Tsai, C. H., and Lin, F. C. 2014. First report of Maize chlorotic mottle virus on sweet corn in Taiwan. Plant Dis. 98:1748.

Dintinger, J., Verger, D., Caiveau, S., Risterucci, A. M., Gilles, J., Chiroleu, F., Courtois, B., Reynaud, B., and Hamon, P. 2005a. Genetic mapping of maize stripe disease resistance from the Mascarene source. Theor. Appl. Genet. 111:347-359.

Doerge, R. W., and Rebai, A. 1996. Significance thresholds for QTL interval mapping tests. Heredity 76:459-464.

Elshire, R. J., Glaubitz, J. C., Sun, Q., Poland, J. A., Kawamoto, K., Buckler, E. S., and Mitchell, S. E. 2011. A robust, simple genotyping-by-sequencing (GBS) approach for high diversity species. PLoS One 6:e19379.

Endelman, J. B., and Jannink, J.-L. 2012. Shrinkage estimation of the realized relationship matrix. G3: Genes Genomes Genet. 2:1405-1413.

Fu, H. H., and Dooner, H. K. 2002. Intraspecific violation of genetic colinearity and its implications in maize. Proc. Natl. Acad. Sci. USA 99: 9573-9578.

Glaubitz, J. C., Casstevens, T. M., Lu, F., Harriman, J., Elshire, R. J., Sun, Q., and Buckler, E. S. 2014. TASSEL-GBS: A high capacity genotyping by sequencing analysis pipeline. PLoS One 9:e90346.

Gowda, M., Das, B., Makumbi, D., Babu, R., Semagn, K., Mahuku, G., Olsen, M. S., Bright, J. M., Beyene, Y., and Prasanna, B. M. 2015. Genome-wide association and genomic prediction of resistance to maize lethal necrosis disease in tropical maize germplasm. Theor. Appl. Genet. 128:1957-1968.

Haley, C. S., and Knott, S. A. 1992. A simple regression method for mapping quantitative trait loci in line crosses using flanking markers. Heredity 69: 315-324.

Hilker, F. M., Allen, L. J. S., Bokil, V. A., Briggs, C. J., Feng, Z. L., Garrett, K. A., Gross, L. J., Hamelin, F. M., Jeger, M. J., Manore, C. A., Power, A. G., Redinbaugh, M. G., Rua, M. A., and Cunniffe, N. J. 2017. Modeling virus coinfection to inform management of maize lethal necrosis in Kenya. Phytopathology 107:1095-1108.

Jampatog, S., Thung-Ngean, M., Balla, C., Boonrumpun, P., Mekarun, A., Jompuk, C., and Kaveeta, R. 2010. Evaluation of improved maize populations and their diallel crosses for yield. Kasetsart J. Nat. Sci. 44:523-528.

Jensen, S. G., Wysong, D. S., Ball, E. M., and Higley, P. M. 1991. Seed transmission of maize chlorotic mottle virus. Plant Dis. 75:497-498.

Jones, M., Boyd, E., and Redinbaugh, M. 2011. Responses of maize (Zea mays L.) near isogenic lines carrying Wsm1,Wsm2, and Wsm3 to three viruses in the Potyviridae. Theor. Appl. Genet. 123:729-740.

Jones, M. W., Redinbaugh, M. G., Anderson, R. J., and Louie, R. 2004. Identification of quantitative trait loci controlling resistance to Maize chlorotic dwarf virus. Theor. Appl. Genet. 110:48-57.

Jones, M. W., Redinbaugh, M. G., and Louie, R. 2007. The Mdm1 locus and maize resistance to Maize dwarf mosaic virus. Plant Dis. 91:185-190.

Kaeppler, S. M., Galusha, D. D., Thomas-Compton, M., Doupnik, B., Jensen, S., and Compton, W. A. 1998. Registration of N211, N217, and N218 parental inbred lines of maize. Crop Sci. 38:289.

Knott, S. A., and Haley, C. S. 2009. Aspects of maximum likelihood methods for the mapping of quantitative trait loci in line crosses. Genet. Res. 60: 139-151.

Lander, E. S., and Botstein, D. 1989. Mapping mendelian factors underlying quantitative traits using RFLP linkage maps. Genetics 121:185-199.

Law, M. D., Moyer, J. W., and Payne, G. A. 1989. Effect of host resistance on pathogenesis of maize dwarf mosaic virus. Phytopathology 79:757-761.

Lei, J. D., and Agrios, G. N. 1986. Mechanisms of resistance in corn to maize dwarf mosaic virus. Phytopathology 76:1034-1040.

Leng, P., Ji, Q., Asp, T., Frei, U. K., Ingvardsen, C. R., Xing, Y., Studer, B., Redinbaugh, M., Jones, M., Gajjar, P., Liu, S., Li, F., Pan, G., Xu, M., and Lübberstedt, T. 2017. Auxin binding protein 1 reinforces resistance to Sugarcane mosaic virus in maize. Mol. Plant 10:1357-1360.

Lin, J.-Z., and Ritland, K. 1996. The effects of selective genotyping on estimates of proportion of recombination between linked quantitative trait loci. Theor. Appl. Genet. 93:1261-1266.

Liu, Q., Liu, H., Gong, Y., Tao, Y., Jiang, L., Zuo, W., Yang, Q., Ye, J., Lai, J., Wu, J., Lübberstedt, T., and Xu, M. 2017. An atypical thioredoxin imparts early resistance to Sugarcane mosaic virus in maize. Mol. Plant 10: 483-497.

Louie, R. 1986. Effects of genotype and inoculation protocols on resistance evaluation of maize to maize dwarf mosaic virus strains. Phytopathology 76:769-773. 
Louie, R., Jones, M. W., Anderson, R. J., and Redinbaugh, M. G. 2002. Registration of maize germplasm Oh1VI. Crop Sci. 42:991.

Luan, J. W., Wang, F., Li, Y. J., Zhang, B., and Zhang, J. R. 2012. Mapping quantitative trait loci conferring resistance to rice black-streaked virus in maize (Zea mays L.). Theor. Appl. Genet. 125:781-791.

Lukanda, M., Owati, A., Ogunsanya, P., Valimunzigha, K., Katsongo, K., Ndemere, H., and Kumar, P. L. 2014. First report of Maize chlorotic mottle virus infecting maize in the Democratic Republic of the Congo. Plant Dis. 98:1448.

Mahuku, G., Lockhart, B. E., Wanjala, B., Jones, M. W., Kimunye, J. N., Stewart, L. R., Cassone, B. J., Sevgan, S., Nyasani, J. O., Kusia, E., Kumar, P. L., Niblett, C. L., Kiggundu, A., Asea, G., Pappu, H. R., Wangai, A., Prasanna, B. M., and Redinbaugh, M. G. 2015a. Maize lethal necrosis (MLN), an emerging threat to maize-based food security in Sub-Saharan Africa. Phytopathology 105:956-965.

Mahuku, G., Wangai, A., Sadessa, K., Teklewold, A., Wegary, D., Ayalneh, D., Adams, I., Smith, J., Bottomley, E., Bryce, S., Braidwood, L., Feyissa, B., Regassa, B., Wanjala, B., Kimunye, J. N., Mugambi, C., Monjero, K., and Prasanna, B. M. 2015b. First report of Maize chlorotic mottle virus and maize lethal necrosis on Maize in Ethiopia. Plant Dis. 99:1870.

Martin, T., Franchino, J. A., Kreff, E. D., Procopiuk, A. M., Tomas, A., Luck, S., and Shu, G. G. 2010. Major QTLs Conferring Resistance of Corn to Fijivirus. United States Patent Application 20100325750.

Masuka, B., Atlin, G. N., Olsen, M., Magorokosho, C., Labuschagne, M., Crossa, J., Banziger, M., Pixley, K. V., Vivek, B. S., von Biljon, A., Macrobert, J., Alvarado, G., Prasanna, B. M., Makumbi, D., Tarekegne, A., Das, B., Zaman-Allah, M., and Cairns, J. E. 2017. Gains in maize genetic improvement in eastern and southern Africa: I. CIMMYT hybrid breeding pipeline. Crop Sci. 57:168-179.

Miller, M. R., White, A., and Boots, M. 2006. The evolution of parasites in response to tolerance in their hosts: The good, the bad, and apparent commensalism. Evolution 60:945-956.

Nelson, S., Brewbaker, J., and Hu, J. 2011. Pages 1-6 in: Maize Chlorotic Mottle. College of Tropical Agriculture and Human Resources, University of Hawaii at Manoa, Honolulu.

Niblett, C. L., and Claflin, L. E. 1978. Corn lethal necrosis-New virus disease of corn in Kansas. Plant Dis. Rep. 62:15-19.

Phillips, N. J., Uyemoto, J. K., and Wilson, D. L. 1982. Maize chlorotic mottle virus and crop rotation-Effect of sorghum on virus incidence. Plant Dis. 66:376-379.

Quito-Avila, D. F., Alvarez, R. A., and Mendoza, A. A. 2016. Occurrence of maize lethal necrosis in Ecuador: A disease without boundaries? Eur. J. Plant Pathol. 146:705-710.

R Corp Team. 2016. R: A Language and Environment for Statistical Computing. R Foundation for Statistical Computing, Vienna.

Rebaï, A. 1997. Comparison of methods for regression interval mapping in QTL analysis with non-normal traits. Genet. Res. 69:69-74.

Redinbaugh, M. G., and Zambrano Mendoza, J. L. 2014. Control of virus diseases in maize. Pages 391-429 in: Control of Plant Virus Disease: SeedPropagated Crops. G. Lobenstein and N. Katis, eds. Academic Press, Waltham, MA.

Roy, B. A., and Kirchner, J. W. 2000. Evolutionary dynamics of pathogen resistance and tolerance. Evolution 54:51-63.

Semagn, K., Beyene, Y., Babu, R., Nair, S., Gowda, M., Das, B., Tarekenge, A., Mugo, S., Mahuku, G., Worku, M., Warburton, M. L., Olsen, M., and Prasanna, B. M. 2015. Quantitative trait loci mapping and molecular breeding for developing stress resilient maize for sub-Saharan Africa. Crop Sci. 55:1449-1459.

Shaner, G., and Finney, R. E. 1977. The effect of nitrogen fertilization on the expression of slow-mildewing resistance in Knox wheat. Phytopathology 67:1051-1056.

Sillanpää, M. J., and Hoti, F. 2007. Mapping quantitative trait loci from a single-tail sample of the phenotype distribution including survival data. Genetics 177:2361-2377.

Silva, L. C., Cruz, C. D., Moreira, M. A., and Barros, E. G. 2007. Simulation of population size and genome saturation level for genetic mapping of recombinant inbred lines (RILs). Genet. Mol. Biol. 30:1101-1108.

Song, R., and Messing, J. 2003. Gene expression of a gene family in maize based on noncollinear haplotypes. Proc. Natl. Acad. Sci. USA 100: 9055-9060.

Springer, N. M., Ying, K., Fu, Y., Ji, T., Yeh, C.-T., Jia, Y., Wu, W., Richmond, T., Kitzman, J., Rosenbaum, H., Iniguez, A. L., Barbazuk, W. B., Jeddeloh, J. A., Nettleton, D., and Schnable, P. S. 2009. Maize inbreds exhibit high levels of copy number variation $(\mathrm{CNV})$ and presence/absence variation (PAV) in genome content. PLoS Genet. 5:e1000734.

Taylor, J. D., and Butler, D. 2014. ASMap: An (A)ccurate and (S)peedy Linkage Map Construction Package for Inbred Populations That Uses the Extremely Efficient MSTmap Algorithm. R Foundation for Statistical Computing, Vienna.

Vandeplas, A. 2003. Evaluation of Sixty Highland Elite Maize Genotypes for Resistance to Maize rayado fino virus. The Katholieke Universiteit Leuven, Leuven, Belgium.

Van Ooijen, J. W., and Voorrips, R. E. 2006. JoinMap 3.0. In: JoinMap 4.0, Software for the Calculation of Genetic Linkage Maps in Experimental Populations. Kyazma B.V., Wageningen, The Netherlands.

Wang, S., Basten, C. J., and Zheng, Z.-B. 2010. Windows QTL Cartographer 2.51. Department of Statistics, North Carolina State University, Raleigh.

Wangai, A. W., Redinbaugh, M. G., Kinyua, Z. M., Miano, D. W., Leley, P. K., Kasina, M., Mahuku, G., Scheets, K., and Jeffers, D. 2012. First report of Maize chlorotic mottle virus and maize lethal necrosis in Kenya. Plant Dis. 96:1582-1583.

Xie, L., Zhang, J., Wang, Q., Meng, C., Hong, J., and Zhou, X. 2011. Characterization of Maize chlorotic mottle virus associated with Maize lethal necrosis disease in China. J. Phytopathol. 159:191-193.

Zambrano, J. L., Francis, D. M., and Redinbaugh, M. G. 2013. Identification of resistance to Maize rayado fino virus in maize inbred lines. Plant Dis. 97: 1418-1423.

Zambrano, J. L., Jones, M. W., Brenner, E., Francis, D. M., Tomas, A., and Redinbaugh, M. G. 2014a. Genetic analysis of resistance to six virus diseases in a multiple virus-resistant maize inbred line. Theor. Appl. Genet. 127:867-880.

Zambrano, J. L., Jones, M. W., Francis, D. M., Tomas, A., and Redinbaugh, M. G. 2014b. Quantitative trait loci for resistance to Maize rayado fino virus. Mol. Breed. 34:989-996.

Zeng, Z. B. 1994. Precision mapping of quantitative trait loci. Genetics 136: 1457-1468.

Zhang, Z., Ersoz, E., Lai, C.-Q., Todhunter, R. J., Tiwari, H. K., Gore, M. A., Bradbury, P. J., Yu, J., Arnett, D. K., Ordovas, J. M., and Buckler, E. S. 2010. Mixed linear model approach adapted for genome-wide association studies. Nat. Genet. 42:355-360. 